\title{
Research of the launch vehicle design made of composite materials under the aerodynamic, thermal and acoustic loadings
}

\author{
Denis Davydovich ${ }^{1}$, Michael Dron ${ }^{1}$, Konstantin Zharikov ${ }^{1}$, and Yulia Iordan $^{1, *}$ \\ ${ }^{1}$ Omsk State Technical University, 644050 Omsk, Russia
}

\begin{abstract}
The experimental research of the carbon composite material sample of payload fairing half structural element was carried out under different types of loading. Mathematical and physical modeling of the sample loading using aerodynamic flow was conducted. Heat loading was researched by the method of a thermal analysis during which typical heat dots corresponding to the changes in the sample structure were determined. Ultrasonic influence on the sample characteristics was considered. As a result, the value of heat leak to the structure surface while moving in the atmospheric phase of the descent was determined.
\end{abstract}

\section{Introduction}

The technique described in $[1,2]$ is proposed for solving the problem of minimizing the exclusion zones under the exhaust parts of the rockets, made of composite materials (CM). According to this technique, we suggest to modify the material of units made of $\mathrm{CM}$, such as the payload fairing half, due to additional energy effects for achieving the fine phase of the structure or for completing the combustion. The method is based on determining the missing quantity of heat as the difference between the incoming and desired heat fluxes. Pyrotechnic composition (PC) as possible additional sources are considered. The assessment of the required mass of the $\mathrm{PC}$ and the temperature increase of the structure are presented in [3]. This technique is described in [4], where titanium parts are used as the destructive elements.

The results given in $[5,6]$ show that ultrasonic treatment leads to a change in the structure of a solid, and can significantly reduce energy consumption for the implementation phase transitions.

The aim of this work is to study the influence of additional energy sources on the structure of the sample with the purpose to achieve maximum destruction.

* Corresponding author: iordanyuliya@gmail.com 


\section{Materials and methods}

The sample of the payload fairing half structural element is a carbon fiber based on carbon tape LU-P-0,1/A and binders. Table 1 presents the composition of the binder according to [7].

Table 1. The composition of the binder.

\begin{tabular}{|c|c|}
\hline Component name & Mass fraction, $\%$ \\
\hline Resin EN-6 & 77.0 \\
\hline Furfurylglycidyl ether & 15.0 \\
\hline The catalyst UP 605/3 & 3.0 \\
\hline Resin SF-341-A & 5.0 \\
\hline
\end{tabular}

Mathematical modelling of the aerodynamic loading was carried out according to [8-10] for the cases of flight of payload fairing half at angles of attack of $0^{\circ}, 90^{\circ}$ and $270^{\circ}$. The motion of the centre of mass, without regard to motion relative to the centre of mass, without taking into account the rotation of the Earth is missing, was considered.

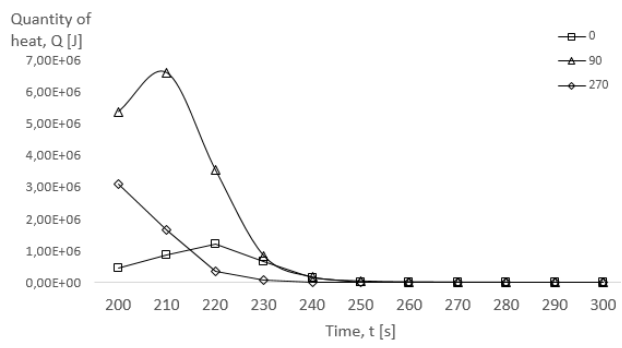

a

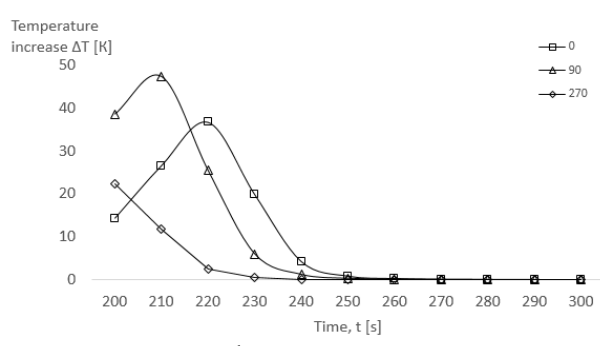

b

Fig. 1. a) Graph of the quantity of heat received by the payload fairing half during the descent from time; b) growth graph of the surface temperature of the structure during the descent.

For physical modelling of aerodynamic heating a bench, providing pre-heating of the sample to a temperature corresponding to a given height was designed. This bench can make the required ram-air flow to simulate the process of blowing with the purpose to determine the magnitude of heat losses. The sample with sizes $40 \times 40 \times 3 \mathrm{~mm}$ was pre-heated by $0.8 \mathrm{~mm}$-thick nichrome thread with to a temperature of $3000 \mathrm{C}$. Thermocouples, fixed in front of the sample and behind it, transferred the data to a personal computer with an interval of $0.5 \mathrm{~s}$. The system of flow simulation provided a given rate of air leak. The experiments were conducted at atmospheric pressure and ambient temperature of $22.5^{\circ} \mathrm{C}$.

The study of thermal loading of the sample was carried out by using a thermal analysis instrument STA 449 F3 Jupiter (Netzsch, Gremany). The sample with mass $19.595 \mathrm{mg}$ was placed into an open corundum crucible and was heated with a heating rate of $10 \mathrm{~K} / \mathrm{min}$ in airflow $100 \mathrm{ml} / \mathrm{min}$.

The experimental bench described in [11], allows to simultaneously simulating the aerodynamic, thermal and acoustic impacts on the test sample. The supply of extra energy in the form of ultrasound exposure leads to a change in the coefficient of thermal conductivity, burning rate, etc., which contributes to the achievement of the research goal. 


\section{Results}

The results of mathematical and physical modelling are represented in Figures 1 and 2, relatively. During thermal decomposition of the sample on the curve thermogravimetry (TG) three stages of mass loss are determined; the second and third stages of the mass loss curve of differential scanning calorimetry (DSC) correspond to successive exothermic peaks (Figure 3). Based on the results of the preliminary experimental studies, ultrasonic treatment on the sample leads to the increase of heat transfer coefficients from the sample to the flow up to $15 \%$ of the nominal value.

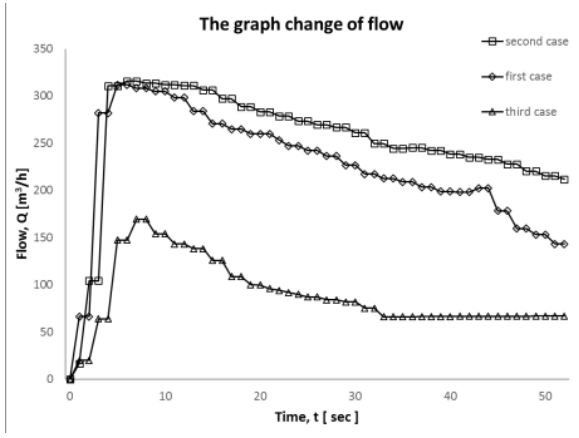

a)

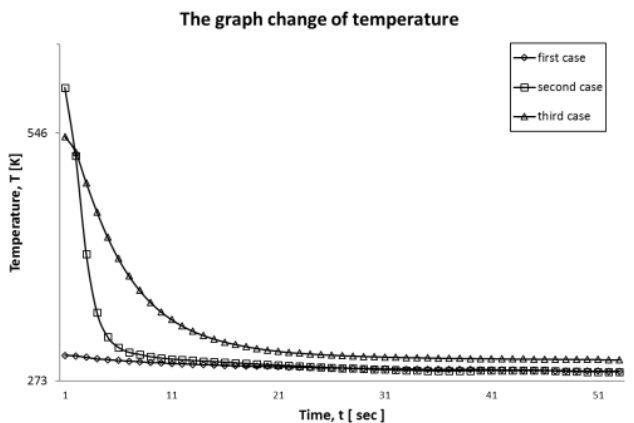

b)

Fig. 2. a) Graph of consumption of the aerodynamic flow; b) graph of temperature change of the sample surface during the blowing of the aerodynamic flow.

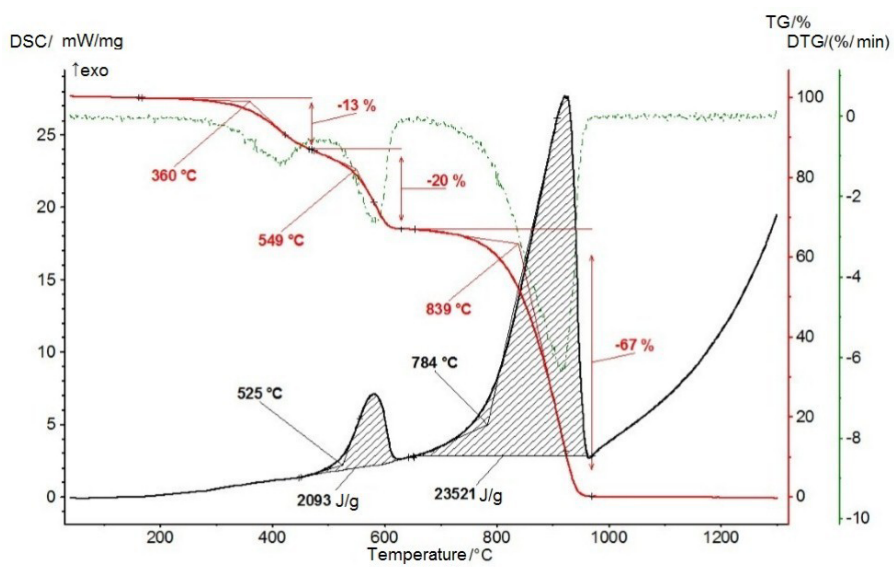

Fig. 3. The thermogram of the mass change (TG), rate of mass loss (DTG) and the rate of heat emission (DSK).

\section{Discussion}

Based on the calculation results presented in Figure 1, it is shown that the value of heat leakage to the surface of the structural element of the payload fairing half is changes depending on the angle of attack and the rate of descent. The maximum increase in temperature from aerodynamic heating in the part from 60 to $0 \mathrm{~km}$ for the considered trajectory case is 47 degrees (without entrainment of heat).

The experimental studies on modelling of aerodynamic load have shown that there is a big heat loss from the surface of the sample, particularly, from the heating element. 
As it can be seen from the experiments on thermal loading, while increasing temperature up to $1000^{\circ} \mathrm{C}$, coal threads constituting the carbon tape of the test sample design, are completely burned. This process is accompanied by considerable heat emission, the value of which is comparable to the calorific value of coal.

The mechanism of changes in the structure of the sample under the acoustic effect is known and is explained by the process of excitation and propagation in layers of the ultrasonic vibrations material, which are periodically alternating phases of compression and rarefaction of the domain. A possible subject of the further research is the determining of the optimal parameters of acoustic influence leading to the destruction of the structure.

\section{Conclusions}

According to the study, we can draw the following conclusions:

1. Simulation of aerodynamic flow is accompanied by significant heat losses that must be considered when choosing sources of thermal loading.

2. To bring the structure to finely disperse phase is required to heat the material of the structure to a temperature of $1000^{\circ} \mathrm{C}$.

3. Ultrasonic effect contributes to the destruction of the sample at lower energy cosumption. To bring the sample to the maximum possible destruction we need to find the certain parameters of ultrasonic influence.

It is necessary to define the optimal ratio of acoustic and thermal energy acting on the sample structure to provide its destruction.

The authors express their acknowledgment to the Professor V. Trushlyakov

The research was supported by the RSF grant for the project "Development of scientific-technical fundamentals of the combustion of the separated elements of space rockets with the goal of reducing the acreage of the impact areas" the Agreement No. 16-19-10091 18.05.2016.

\section{References}

1. V. Trushlyakov, Ya. Shatrov, D. Lempert, Yu. Iordan, V. Zarko, RF Patent № 2581636 (2016)

2. V. Trushlyakov, Ya. Shatrov, , RF Patent № 2585395 (2016)

3. D. Lempert, D. B., Trushlyakov, V. I. and Zarko V. E., CESW 51, 5, 619 (2015)

4. K. Monogarov, A. Pivkina, N. Murav'ov, Combustion and explosion 7, 327 (2014)

5. H. Puga, S. Costa, J. Barbosa, S. Ribeiro, M. Prokic, J MATER PROCESS TECH 211, 11, 1729 (2011)

6. V. Trushlyakov, V. Kudentsov, I. Lesnyak and etc., Project Report № 2.1.2/13519, OmSTU (2011)

7. State Standard 28006-88 (1989)

8. A. Tewari, J Spacecr Rockets 46, 2, 299 (2009)

9. A. Glazunov, Tomsk State University Journals 4, 79 (2011)

10. D. Balakrishnan, J. Kurian, J Spacecr Rockets 51, 4,1319 (2014)

11. V. Trushlyakov, K. Zharikov, M. Dron’, Yu. Iordan, D. Davydovich, , RF Patent № 2016134556 (2016) 